\title{
Adenovirus-related gastric lesion in a patient with a bone marrow transplant
}
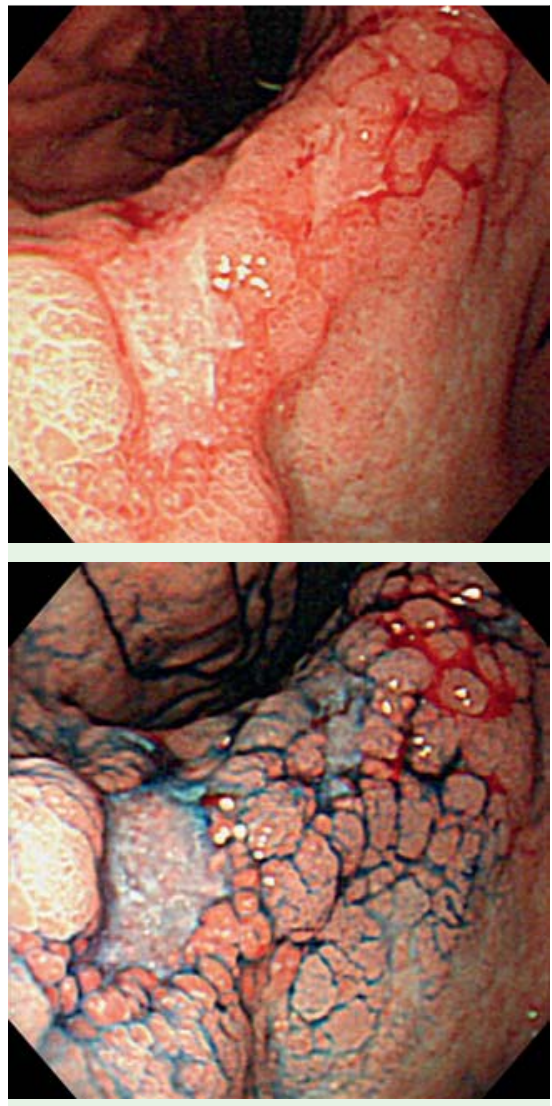

Fig. 1 a, b Endoscopic images showing irregular ulcers and the friable nodular mucosa (a standard; $\mathbf{b}$ indigo-carmine staining).

Adenovirus is one the many pathogens and opportunistic agents that may cause serious infection in immunocompromised hosts or in patients undergoing immunosuppressive treatment for organ and tissue transplantation [1]. Gastrointestinal lesions associated with adenovirus infection have been rarely reported, probably because of a lack of awareness.

A 45-year-old man was diagnosed as having acute monocytic leukemia. Following complete remission by intensive chemotherapy, he received a reduced-intensity allergenic stem cell transplant. Thereafter he was treated with ciclosporin. After 12 months, the patient was admitted to the hospital with hemorrhagic cystitis. He underwent upper gastrointestinal endoscopy as he had complained of epigastric discomfort and pain on swallowing. Endoscopy revealed irregular-shaped ulcers surrounded by fragile nodular mucosa in

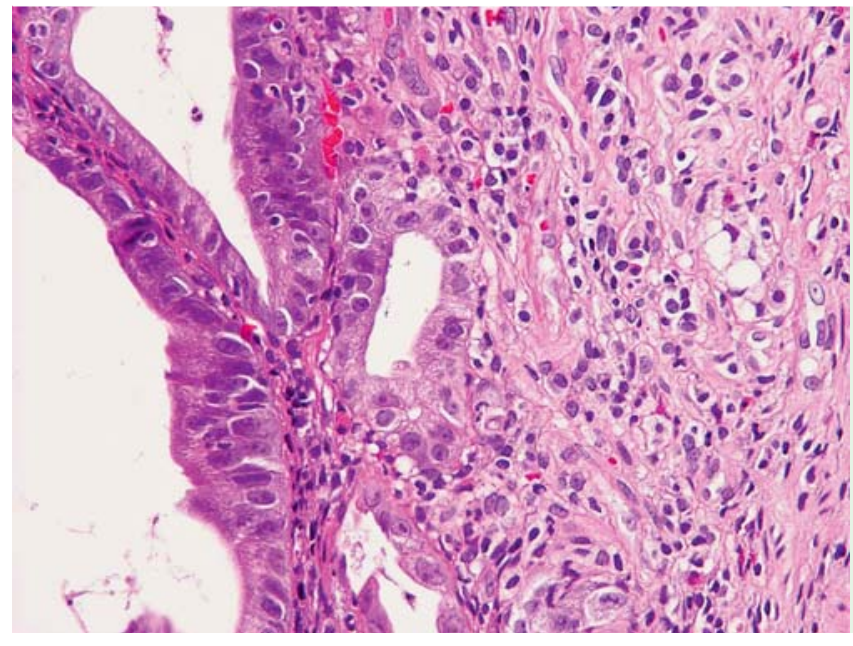

Fig. 2 Histological section of the lesion edge showing inflammation and degenerating gastric epithelial cells, predominantly surface crypt and foveolar epithelium (hematoxylin and eosin, magnification $\times 400$ ).

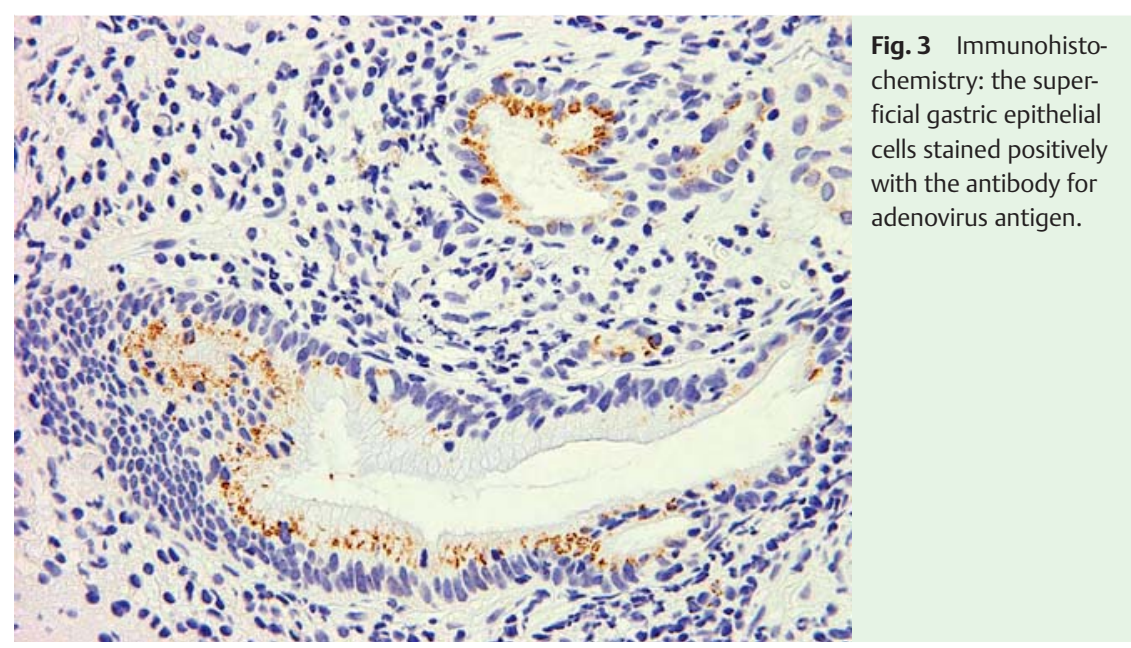

the lesser curvature and anterior wall, extending from the lower gastric body towards the angle ( $\bullet$ Fig. 1 ).

Endoscopic biopsy specimens taken from the border of the lesions demonstrated mucosal inflammatory infiltrate and degeneration of gastric epithelial cells (๑ Fig. 2).

There were no intranuclear inclusion bodies in the stromal cells in the biopsy specimens, including the endothelium, suggestive of cytomegalovirus (CMV) infection. Immunohistochemical analysis was performed using specific antibodies against CMV, Epstein-Barr virus (LMP1), herpes simplex and zoster, human papillomavirus, and adenovirus antigen. Of note, the superficial gastric epithelial cells showed positive immunostaining with the antibody for adenovirus antigen ( $\bullet$ Fig. 3 ).
The patient was treated with a proton pump inhibitor (omeprazole) for 8 weeks. Although his clinical symptoms have resolved, he continues to be on antiviral therapy.

Typical adenovirus-associated gastrointestinal disorders are characterized by histological changes involving the surface epithelium, the features of which include cellular degeneration (particularly of mucous cells), loss of orientation, and vacuolization [1,2], whereas CMV infection predominantly affects the gastrointestinal stroma, in particular the endothelium and rarely involves epithelial cells [1].

\section{Competing interests: None}

Endoscopy_UCTN_Code_CCL_1AB_2AC_3AZ 
N. Inoue ${ }^{1^{*}}, \mathrm{H}$. Isomoto ${ }^{1^{*}}$, N. Yamaguchi ${ }^{1}$, T. Hayashi ${ }^{2}$, Y. Sawayama ${ }^{3}$, K. Ohnita ${ }^{1}$, F. Takeshima', S. Shikuwa ${ }^{1}$, Y. Miyazaki ${ }^{3}$, K. Nakao ${ }^{1}$

1 Department of Gastroenterology and Hepatology, Nagasaki University Hospital, Nagasaki, Japan

2 Department of Pathology, Nagasaki University Hospital, Nagasaki, Japan

3 Department of Hematology, Nagasaki University Hospital, Nagasaki, Japan

* Each author contributed equally to this work.

\section{References}

1 Yan Z, Nruyen S, Poles $M$ et al. Adenovirus colitis in human immunodeficiency virus infection. Am J Surg Pathol 1998; 22: $1101-1106$

2 Janoff EN, Orestein JM, Manischewitz JF et al. Adenovirus colitis in the acquired immunodeficiency syndrome. Gastroenterology 1991; 100: 976-979

\section{Bibliography}

DOI $10.1055 / \mathrm{s}-0030-1255943$

Endoscopy 2010; 42: E328 - E329

(c) Georg Thieme Verlag KG Stuttgart · New York . ISSN 0013-726X

\section{Corresponding author}

\section{H. Isomoto}

Department of Gastroenterology and Hepatology Nagasaki University Hospital

1-7-1 Sakamoto

Nagasaki 852-8501

Japan

Fax: +81-95-849-7282

hajimei2002@yahoo.co.jp 